\title{
Do "regionalismo aberto" à proposta de uma comunidade sul-americana das nações: o processo histórico de criação da UNASUL (União das Nações Sul-Americanas)
}

\author{
From "open regionalism" to the proposal of a South American community \\ of nations: the historical process of creation of UNASUR (Union of South \\ American Nations)
}

\author{
Carolina de Oliveira \\ UNISC - Universidade de Santa Cruz do Sul- Santa Cruz do Sul - Rio Grande do Sul - \\ Brasil \\ ORCID https://orcid.org/0000-0002-2495-4832
}

\section{Marco André Cadoná}

Universidade de Santa Cruz do Sul - Santa Cruz do Sul - Rio Grande do Sul - Brasil ORCID https://orcid.org/0000-0003-1580-5234

Resumo: A UNASUL é um projeto de integração entre países da América do Sul, criado em 2008 a partir da assinatura do Tratado Constitutivo da UNASUL, que tem como signatários: Argentina, Bolívia, Brasil, Chile, Colômbia, Equador, Guiana, Paraguai, Peru, Suriname, Uruguai e Venezuela. O artigo considera aspectos históricos da criação da UNASUL para analisar mudanças que ocorreram nas concepções de integração sulamericana a partir da "guinada à esquerda" observada na década de 2000 na América do Sul. Busca-se, nesse sentido, compreender como a ascensão de governos nacionais comprometidos com forças sociais e políticas que se opuseram aos projetos neoliberais de reestruturação do capitalismo, adotados na América do Sul durante a década de 1990, repercutiu no processo histórico de constituição da UNASUL.

Palavras-Chave: Integração Sul-americana; UNASUL; regionalismo aberto; comunidade sul-americana.

Abstract: UNASUR is a project of integration between countries of South America, created in 2008 from the signing of the Constitutive Treaty of UNASUR, which has as signatories: Argentina, Bolivia, Brazil, Chile, Colombia, Ecuador, Guyana, Paraguay, Peru, Suriname, Uruguay and Venezuela. The article considers historical aspects of the creation of UNASUR to analyze changes that occurred in the conceptions of South American integration starting from the "left turn" observed in the decade of 2000 in South America. In this sense, the aim is to understand how the rise of national governments committed to social and political forces that opposed the neoliberal projects of capitalist restructuring adopted in South America during the 1990s, had repercussions on the historical process of constitution of UNASUR. 
Do "regionalismo aberto" à proposta de uma comunidade sul-americana das nações: o processo histórico de criação da UNASUL (União das Nações Sul-Americanas).

Keywords: South American integration; UNASUL; open regionalism; South American community.

\section{Introdução}

A discussão sobre projetos de integração entre países sul-americanos remete a períodos anteriores ao século XX. Contudo, somente a partir da segunda metade do século XX é que os movimentos de integração ganharam significado histórico. A partir daquele período, já num contexto histórico de maior consciência quanto à situação de dependência econômica dos países sul-americanos, instituições como a CEPAL (Comissão Econômica para América Latina), mas, também, os próprios governos nacionais, passaram a discutir com maior interesse a concretização de projetos de integração regional. No horizonte daqueles projetos, o interesse em impulsionar o crescimento econômico, formando-se blocos com maior capacidade de negociação no cenário internacional, numa perspectiva de enfrentamento, progressivo, às assimetrias existentes na relação com o "centro industrializado" (VIEIRA, 2015, p. 32).

Foi naquele contexto histórico que, no início da década de 1960, a ALALC (Associação Latino Americana de Livre Comércio) foi criada, um projeto de integração que, como indica sua própria denominação, pretendia, gradualmente, criar uma área de livre comércio entre os seus países membros: inicialmente, Argentina, Brasil, México, Chile, Paraguai, Peru e Uruguai; mais tarde e ainda na década de 1960, com a também participação da Colômbia, Equador, Bolívia e Venezuela (VIEIRA, 2015, p. 33). A ALALC foi mantida até a década de 1980, demonstrando aquela experiência de integração uma série de dificuldades (observadas ainda durante a década de 1960): heterogeneidade de estrutura e níveis dos países participantes; solidariedade débil; resistências a dinâmicas de abertura das economias nacionais; temor que uma área de livre comércio favorecesse os países maiores; governos autoritários e seus projetos individuais de desenvolvimento econômico (KAPLAN, 1968, p. 188-191).

Diante das dificuldades enfrentadas, a ALALC foi transformada, na década de 1980, em ALADI (Associação Latino-Americana de Integração), resultado do interesse de onze países latino-americanos em dar continuidade ao projeto anterior: Bolívia, Equador, Paraguai, Chile, Colômbia, Peru, Uruguai, Venezuela, Argentina, Brasil e México (VIEIRA, 2015, p. 42). A ALADI, no entanto, nasceu num contexto histórico de crise na América Latina, uma crise econômica e política que expressava os limites dos modelos de desenvolvimento adotados na Região a partir dos anos 1960 (em especial, por regimes autoritários), que naquelas alturas agravavam as contradições sociais e econômicas e, ao mesmo tempo, impulsionavam amplos movimentos sociais e políticos de ruptura com os regimes autoritários e de afirmação de regimes democráticos. A ALADI, assim, perdeu importância no contexto de crise econômica e política da década de 1980 (VIEIRA, 2015, p. 51).

Naquela mesma década de 1980, no entanto, um novo projeto de integração entre países sul-americanos emergiu. Num processo iniciado ainda em 1985, tendo como protagonistas os governos da Argentina e do Brasil, em 1991 foi criado o 
Do "regionalismo aberto" à proposta de uma comunidade sul-americana das nações: o processo histórico de criação da UNASUL (União das Nações Sul-Americanas).

MERCOSUL (Mercado Comum do Sul), integrando Argentina, Brasil, Paraguai e Uruguai. O MERCOSUL perdura até os dias atuais, tendo como membros Argentina, Brasil, Paraguai, Uruguai e Venezuela (suspensa do bloco a partir de dezembro de 2016) e cinco países associados (Chile, Bolívia, Colômbia, Equador e Peru), além de dois países observadores (Nova Zelândia e México) (BRASIL, 2017).

Registre-se, também, a presença da CAN (Comunidade Andina das Nações), formada pela Bolívia, Colômbia, Equador e Peru, um projeto de integração que teve origem ainda em 1969, que apresentou diferentes fases, mas que ainda persiste como projeto de integração entre os Países da Região da Cordilheira dos Andes, na América do Sul (REINOSO, 2000).

A União das Nações Sul-Americanas (UNASUL), assim, é expressão desse esforço histórico de integração entre países latino-americanos e, em especial, sul-americanos. Com sede em Quito, capital do Equador, a UNASUL é considerada uma iniciativa de integração regional que procura associar a soberania e a autonomia dos doze países que a compõem (Argentina, Bolívia, Brasil, Chile, Colômbia, Equador, Guiana, Paraguai, Peru, Suriname, Uruguai e Venezuela), buscando o seu fortalecimento, como está expresso no artigo 2 de seu Tratado Constitutivo:

[...] a UNASUL tem como objetivo construir, de maneira participativa e consensual, um espaço de integração e união no âmbito cultural, social, econômico e político entre seus povos, priorizando o diálogo político, as políticas sociais, a educação, a energia, a infraestrutura, o financiamento e o meio ambiente, entre outros, com vistas a eliminar a desigualdade socioeconômica, alcançar a inclusão social e a participação cidadã, fortalecer a democracia e reduzir as assimetrias no contexto do fortalecimento da soberania e independência dos Estados (UNASUL, 2008).

Note-se, nesse artigo do Tratado Constitutivo da UNASUL, que a integração é compreendida não somente a partir do interesse de criação de uma área de livre comércio, mas, também, como um projeto de integração capaz de impulsionar dinâmicas econômicas, políticas, sociais, culturais, ambientais na América do Sul, com ênfase na diminuição das desigualdades, na inclusão social e participação cidadã, no fortalecimento da democracia. Cabe, nesse sentido, analisar se essa concepção de integração esteve presente desde o início das discussões que resultaram na criação da UNASUL ou, então, se resultou de uma construção histórica e expressiva das mudanças que ocorreram nas orientações políticas e ideológicas nos governos sul-americanos na passagem da década de 1990 para a década de 2000.

\section{Do regionalismo aberto à comunidade sul-americana das nações: o processo histórico de criação da UNASUL}

As discussões sobre um projeto de integração envolvendo todos os países sulamericanos e que resultaram na criação da UNASUL foram iniciadas ainda na primeira metade da década de 1990. Em 1993, por exemplo, os Presidentes dos países do MERCOSUL, mais os presidentes da Colômbia e da Venezuela, criaram a Área de Livre 
Do "regionalismo aberto" à proposta de uma comunidade sul-americana das nações: o processo histórico de criação da UNASUL (União das Nações Sul-Americanas).

Comércio Sul-Americana (ALCSA). Porém, os anos compreendidos entre 2000 e 2004 foram fundamentais para o comprometimento dos países sul-americanos com o projeto de criação da UNASUL. Foi naquele período que ocorreram três encontros bianuais, realizados pelos presidentes sul-americanos, que se tornaram "marcos-chave da transformação da política regional" na América do Sul num período recente (GOMES, 2012).

O primeiro daqueles encontros ("A Primeira Cúpula de Presidentes da América do Sul") ocorreu em setembro de 2000, em Brasília, e contou com a presença dos presidentes do Brasil, da Argentina, da Bolívia, do Chile, da Colômbia, do Equador, da Guiana, do Paraguai, do Peru, do Suriname, do Uruguai e da Venezuela (COMUNICADO DE BRASÍLIA, 2000). Ao final daquela Cúpula, os chefes de Estado publicaram um "Comunicado", versando sobre cinco temas principais: 1. Democracia; 2. Comércio; 3. Infraestrutura e integração; 4. Drogas ilícitas e delitos conexos; 5. Informação, conhecimento e tecnologia.

Em relação à democracia, o Comunicado de Brasília manifestou o comprometimento dos chefes de Estado na América do Sul com a "a paz, a democracia e a integração", considerados "elementos indispensáveis para garantir o desenvolvimento e segurança na região". Ao mesmo tempo, afirmou a positividade do aprofundamento do diálogo entre o MERCOSUL e a CAN, destacando, também, a importância de políticas de combate à pobreza e às desigualdades, a defesa dos direitos humanos, a necessidade de combate às ações que violam os direitos humanos. Especificamente sobre a democracia, o documento afirma:

\begin{abstract}
Os Chefes de Estado coincidiram em que a democracia na América do Sul deve ser reforçada com a permanente promoção e defesa do estado de direito; a aplicação eficiente dos princípios da boa governança; transparência das instituições públicas e dos processos de definição de políticas públicas; combate à corrupção, por meio de medidas legais, administrativas e políticas; reformas e aperfeiçoamento dos serviços judiciários, de modo a consolidar sistemas mais eficazes, transparentes e de amplo acesso para os habitantes dos países sul-americanos; acesso livre à informação sobre as atividades de autoridades públicas, bem como aos recursos administrativos, e aumento dos níveis de competência e promoção da ética e profissionalismo dentro do serviço público (COMUNICADO DE BRASíLIA, 2000).
\end{abstract}

Quanto ao comércio, o Comunicado de Brasília destacou a importância da aproximação da CAN com o MERCOSUL, numa perspectiva de construção de uma área de livre comércio, mas, também, "a importância do processo de liberalização de mercados na América do Sul". Afirmaram os chefes de Estado presentes na Cúpula de 2000 o entendimento de que "o processo de formação de um espaço econômico ampliado na região" deveria ocorrer de acordo "com os princípios do 'regionalismo aberto'", indicando a relevância das negociações envolvendo outras regiões do Planeta, em especial as negociações envolvendo a criação de uma Área de Livre Comércio das Américas (ALCA), além de potenciais negociações com a União Europeia.

Destaque-se, nesse sentido, que naquele momento a posição hegemônica dos governos sul-americanos era favorável ao aprofundamento das relações da América do 
Do "regionalismo aberto" à proposta de uma comunidade sul-americana das nações: o processo histórico de criação da UNASUL (União das Nações Sul-Americanas).

Sul com o Norte, tanto com a Europa, mas, principalmente, com os Estados Unidos, através da ALCA. Sobre essa, inclusive, o Comunicado assim se pronunciou:

[...]. Os Presidentes dos países da América do Sul reafirmaram seu apoio ao processo de expansão e aprofundamento da integração econômica no Hemisfério. Nesse contexto, receberam com satisfação os resultados da $\mathrm{V}$ Reunião Ministerial da ALCA, realizada em Toronto, em novembro de 1999, e reafirmaram seu engajamento na conformação progressiva de uma área de livre comércio nas Américas, cujas negociações deverão estar concluídas, no mais tardar, até 2005, em bases equitativas e equilibradas que assegurem o acesso efetivo a mercados para as exportações provenientes dos países da América do Sul. Os Presidentes decidiram, para tanto, intensificar a coordenação das posições negociadoras dos países sul-americanos (COMUNICADO DE BRASÍLIA, 2000).

Não havia, portanto (e naquele momento), uma posição hegemônica de contrariedade política e ideológica em relação à integração da América do Sul ao projeto de uma área de livre comércio proposta durante a década de 1990 pelos governos dos Estados Unidos. As ponderações existentes, naquele período, se dirigiam às questões relativas à equidade, como princípio e fundamento das discussões sobre a criação de uma área de livre comércio integrando todo o Continente Americano.

Em relação à infraestrutura e integração, o Comunicado de Brasília destacou a existência de um Plano de Ação para a Integração da Infraestrutura Regional na América do Sul, contento sugestões e propostas para a ampliação e a "modernização" da infraestrutura física na América do Sul, especialmente nas áreas de energia, transportes e comunicações, numa perspectiva de criação de "eixos de integração e de desenvolvimento econômico e social para o futuro espaço econômico ampliado da região" (COMUNICADO DE BRASÍLIA, 2000).

Sobre o tema drogas ilícitas e delitos conexos, os chefes de Estado presentes na Cúpula de Brasília "enfatizaram a preocupação com o problema das drogas ilícitas e delitos conexos na região", vinculando esse problema com o contrabando, o tráfico ilícito de armas e o terrorismo. Destacaram a importância da OEA (Organização dos Estados Americanos) no "avanço da luta contra as drogas no Hemisfério" e reafirmaram o compromisso da América do Sul com princípios que regem a cooperação internacional nesse campo: "responsabilidade compartilhada, entre os países produtores, de trânsito ou consumidores, e tratamento equilibrado, que confira igual ênfase aos aspectos de controle da oferta, de redução da demanda e de tratamento de dependentes" (COMUNICADO DE BRASÍLIA, 2000).

Por fim, sobre informação, conhecimento e tecnologia, pressupondo o crescente desenvolvimento da "sociedade da informação", os chefes de Estado presentes na Cúpula de Brasília mostraram preocupações com o desenvolvimento de políticas de educação e de acesso às tecnologias de informação. Nessa direção, destacaram "a importância de que a aceleração do acesso à nova era da sociedade da informação e do conhecimento seja respaldada em seus países pelo fortalecimento de um sistema de educação continuado que assegure a educação [...] aos mais amplos setores da sociedade", assegurando "acesso sem restrições ao conhecimento e à informação" 
Do "regionalismo aberto" à proposta de uma comunidade sul-americana das nações: o processo histórico de criação da UNASUL (União das Nações Sul-Americanas).

(COMUNICADO DE BRASÍLIA, 2000). E, reconhecendo a necessidade de avanço científico e tecnológico na Região, afirmaram a importância de ações conjuntas, no sentido do fortalecimento das competências e das infraestruturas nacionais de pesquisa, de construção do conhecimento e de informação (COMUNICADO DE BRASÍLIA, 2000).

O segundo encontro dos presidentes sul-americanos aconteceu na cidade de Guayaquil, no Equador, em julho de 2002, contando com a presença dos Presidentes da Argentina, da Bolívia, do Brasil, da Colômbia, do Chile, do Equador, do Paraguai, do Peru e da Venezuela (além de representantes do Uruguai, da Guiana e do Suriname) (CONSENSO DE GUAYAQUIL, 2002). Ao final daquele encontro, os representantes dos países participantes publicaram um documento denominado "Consenso de Guayaquil sobre Integração, Segurança e Infraestrutura para o Desenvolvimento".

O Consenso de Guayaquil inicia reafirmando os resultados da Cúpula de Brasília, realizada em 2000, inclusive destacando a importância da continuidade nas discussões sobre a integração de toda a América do Sul. Também enfatiza a importância da ampliação e do fortalecimento das políticas de desenvolvimento da infraestrutura na América do Sul, numa perspectiva integracionista (com ênfase na ideia de um "regionalismo aberto"), dando destaque à Iniciativa para a Integração da Infraestrutura Regional da América do Sul (IIRSA):

Os Chefes de Estado reafirmaram a vigência e a importância estratégica da Iniciativa para a Integração da Infraestrutura Regional da América do Sul (IIRSA), como instrumento viável para a integração multissetorial, tanto das distintas áreas costeiras do Caribe, do Pacífico e do Atlântico, quanto das zonas internas da América do Sul, entre si, e ratificaram o mais amplo apoio à sua implementação, como um enfoque acertado para: a) promover e facilitar o crescimento e o desenvolvimento econômico e social da América do Sul; b) melhorar a competitividade internacional da região, incrementando sua participação na economia mundial e enfrentando melhor os desafios que se impõem com a globalização e c) fortalecer a integração e a cooperação regional mediante a ampliação de mercados, a convergência de políticas públicas e a aproximação social e cultural da América do Sul (CONSENSO DE GUAYAQUIL, 2002. Tradução dos autores).

E, assim como na Cúpula de Brasília, ao destacarem os avanços nas negociações entre o MERCOSUL e a CAN, os chefes de Estado presentes em Guayaquil também destacaram a necessidade de uma concertação política dos países sul-americanos visando as negociações da ALCA; numa perspectiva não de questionamento desse processo integrativo, mas, antes, de discussão sobre estratégias de participação e de afirmação de interesses nacionais (e, mesmo, da América do Sul):

[...]. Os Presidentes acordaram, no que diz respeito à participação dos países com pequenas economias nas negociações da ALCA, que este processo deve considerar apropriadamente as circunstâncias, necessidades, condições econômicas e oportunidades dos mesmos. Para isso, respaldaram a necessidade de encontrar modalidades apropriadas dirigidas ao fortalecimento da capacidade destes países para participarem no processo de negociação da ALCA e implementar, plena e suficientemente, os resultados que se alcancem nessas negociações (CONSENSO DE GUAYAQUIL, 2002. Tradução dos autores). 
Do "regionalismo aberto" à proposta de uma comunidade sul-americana das nações: o processo histórico de criação da UNASUL (União das Nações Sul-Americanas).

É importante destacar que os dois primeiros encontros realizados pelos chefes de Estado visando discutir um projeto de integração com a participação de todos os países da América do Sul ocorreram ainda num contexto histórico em que os governantes, em sua maioria, eram os mesmos que, durante a década de 1990, orientaram suas políticas governamentais a partir dos pressupostos do ideário neoliberal. Não é por acaso, nesse sentido, que nos dois documentos resultantes daqueles dois encontros observa-se uma "naturalização da ALCA", no sentido de aceitar aquele projeto de área de livre comércio como um projeto que seria, afinal, objetivado no ano de 2005 (naquele período já estabelecido aquele ano como a criação da ALCA), e a afirmação de dinâmicas de integração a partir da perspectiva do "regionalismo aberto".

O conceito de "regionalismo aberto" passou a ser utilizado pela CEPAL a partir dos anos 1990, como forma de incentivar, ao mesmo tempo, processos de integração econômica na América Latina e estratégias de competitividade econômica num contexto de reestruturação do capitalismo e de mundialização do capital. Na definição da CEPAL, o regionalismo aberto diz de um processo de interdependência no nível regional, visando fortalecer a competitividade dos países numa economia internacionalizada:

\begin{abstract}
Sin embargo, por lo menos desde el punto de vista conceptual, es posible postular que los compromisos integradores entre Países pueden ser no sólo compatibles con sino también funcionales para el objetivo de lograr crecientes niveles de competitividad internacional. De hecho, ninguno de los Países desarrollados o en desarrollo que han asumido compromisos integradores los han planteado como alternativas a una inserción más dinámica en la economía internacional, sino como procesos complementarios para cumplir ese propósito. En los Países de ambos grupos se sostiene más bien que su finalidad es la instauración de una economía internacional más abierta y transparente: los procesos de integración serían los futuros cimientos de una economía internacional libre de proteccionismo y de trabas al intercambio de bienes y servicios (CEPAL, 1994).
\end{abstract}

Como assinala Corazza (2006), o conceito de "regionalismo aberto" promoveu "rupturas na linha histórica do pensamento da CEPAL" (CORAZZA, 2006, p. 149). Até a década de 1980, a CEPAL se comprometia com uma visão de integração regional que contemplava a inserção dos países latino-americanos na dinâmica de globalização, mas, no entanto, de forma a proteger os interesses das economias nacionais naquela dinâmica. A integração regional era vista, pois, "como um meio de proteção e de fortalecimento das economias regionais para garantir uma inserção mais segura e uma competitividade global em condições mais igualitárias", numa perspectiva em que o próprio Estado conservava "um papel estratégico na promoção" do desenvolvimento (CORAZZA, 2006, p. 149). Na concepção de desenvolvimento e de integração regional inerente ao conceito de "regionalismo aberto", no entanto:

[...] não se trata mais de alterar os mecanismos de mercado [...] mas de aceitar suas exigências e interesses, aperfeiçoando-os e se integrando a eles sem restrições, através da abertura e da liberalização amplas e profundas das economias latino-americanas. Para o "regionalismo aberto", a integração 
Do "regionalismo aberto" à proposta de uma comunidade sul-americana das nações: o processo histórico de criação da UNASUL (União das Nações Sul-Americanas).

\begin{abstract}
regional não tem mais como objetivo proteger os interesses dos Paísesmembros, mas opera como uma etapa e um meio para sua própria superação em favor de uma economia internacional aberta e livre de qualquer restrição ou acordo regional. Ao contrário do que propunha o pensamento histórico estrutural da CEPAL de promover o crescimento "para dentro", o "regionalismo aberto" parece ter invertido a pauta, ao propor voltar-se "para fora" e adequar-se integralmente às exigências "de fora". O papel do Estado também se alterou radicalmente, na medida em que lhe cabe, agora, não mais promover a industrialização nacional e o desenvolvimento, mas, sim, a abertura das economias e a competitividade internacional (CORAZZA, 2006, p. 149-50).
\end{abstract}

Entende-se, portanto, por que a ALCA não foi questionada nas duas primeiras reuniões que os chefes de Estado realizaram no começo dos anos 2000, numa perspectiva de criação de um projeto de integração envolvendo todos os países da América do Sul. Não havia naquele período, pelo menos como concepção predominante, uma compreensão favorável ao rompimento com dinâmicas de abertura das economias nacionais, com uma maior integração no processo de mundialização do capital, com um alinhamento dos pressupostos neoliberais que, inclusive, eram defendidos por instituições internacionais e representativas dos interesses dos capitais mundializados (FMI e Banco Mundial, em especial).

Essas concepções começaram a apresentar alterações significativas a partir da "Terceira Cúpula Presidencial", realizada em Cusco, no Peru, no dia 08 de dezembro de 2004. Note-se, de imediato, que em 2004 presidentes vinculados a forças sociais e políticas historicamente comprometidas com os setores organizados das classes populares e de trabalhadoras na América Latina já tinham assumido os governos nacionais. É o caso, por exemplo, de Luís Inácio Lula da Silva, eleito no Brasil em 2002, e de Néstor Kirchner, eleito na Argentina em 2003. Essas mudanças aparecem já no preambulo da Declaração de Cusco sobre a Comunidade Sul-Americana de Nações, ao indicar líderes históricos e comprometidos com dinâmicas de maior independência da América Latina:

Os Presidentes dos Países da América do Sul, reunidos na cidade de Cusco, por ocasião da celebração das façanhas libertadoras de Junín e Ayacucho e da convocação do Congresso Anfictiônico do Panamá, seguindo o exemplo do Libertador Simón Bolívar, do Grande Marechal de Ayacucho, Antonio José de Sucre, do Libertador José de San Martín, de nossos povos e heróis independentistas que construíram, sem fronteiras, a grande Pátria Americana e interpretando as aspirações e anseios de seus povos a favor da integração, unidade e construção de um futuro comum, decidimos formar a Comunidade Sul-americana de Nações (DECLARAÇÃO DE CUSCO, 2004. Grifo no Original. Tradução dos autores).

Organizado em três momentos, a Declaração de Custo tornou pública a criação da Comunidade Sul-Americana de Nações, versou sobre os processos que deveriam ser impulsionados pelo "espaço sul-americano" e definiu algumas condições institucionais 
Do "regionalismo aberto" à proposta de uma comunidade sul-americana das nações: o processo histórico de criação da UNASUL (União das Nações Sul-Americanas).

de funcionamento da Comunidade criada. Para fins da análise apresentada neste artigo, cabe destacar os dois primeiros pontos.

Em relação à Comunidade Sul-Americana das Nações, a Declaração de Cusco assim se referiu:

A história compartilhada e solidária de nossas nações, que desde as façanhas da independência têm enfrentado desafios internos e externos comuns, demonstra que nossos Países possuem potencialidades ainda não aproveitadas tanto para utilizar melhor suas aptidões regionais quanto para fortalecer as capacidades de negociação e projeção internacionais;

O pensamento político e filosófico nascido de sua tradição, que, reconhecendo a primazia do ser humano, de sua dignidade e direitos, a pluralidade de povos e culturas, consolidou uma identidade sul-americana compartilhada e valores comuns, tais como: a democracia, a solidariedade, os direitos humanos, a liberdade, a justiça social, o respeito à integridade territorial e à diversidade, a não-discriminação e a afirmação de sua autonomia, a igualdade soberana dos Estados e a solução pacífica de controvérsias;

[...]

A convicção de que o acesso a melhores níveis de vida de seus povos e à promoção do desenvolvimento econômico não pode reduzir-se somente a políticas de crescimento sustentável da economia, mas compreender também estratégias que, juntamente com uma consciência ambiental responsável e o reconhecimento das assimetrias no desenvolvimento de seus países, assegurem uma distribuição de receita mais justa e equitativa, o acesso à educação, a coesão e a inclusão social, bem como a preservação do meio ambiente e a promoção do desenvolvimento sustentável.

Nesse contexto, o desenvolvimento das regiões interiores do espaço sulamericano contribuirá para aprofundar o projeto comunitário, bem como para melhorar a qualidade de vida dessas zonas que se encontram entre as de menor desenvolvimento relativo.

Seu compromisso essencial com a luta contra a pobreza, a eliminação da fome, a geração de emprego decente e o acesso de todos à saúde e à educação, como ferramentas fundamentais para o desenvolvimento de seus povos;

[...]

Sua determinação de desenvolver um espaço sul-americano integrado no âmbito político, social, econômico, ambiental e de infraestrutura, que fortaleça a identidade própria da América do Sul e que contribua, a partir de uma perspectiva subregional e em articulação com outras experiências de integração regional, para o fortalecimento da América Latina e do Caribe e Ihes outorgue uma maior gravitação e representação nos foros internacionais;

Nossa convicção é no sentido de que a efetivação dos valores e interesses compartilhados que nos unem, além de comprometer nossos Governos, somente encontrará viabilidade na medida em que os povos assumam o papel protagonista que lhes corresponde nesse processo. A integração sulamericana é e deve ser a integração dos povos (DECLARAÇÃO DE CUSCO, 2004. Tradução dos autores).

Ainda que longa, a citação é muito representativa, pois indica não somente uma concepção de desenvolvimento que integra diferentes dimensões, além da econômica (ambiental, cultural, social, política), mas, também, o interesse de, através da integração comunitária entre as nações sul-americanas, conquistar espaços de poder no contexto 
Do "regionalismo aberto" à proposta de uma comunidade sul-americana das nações: o processo histórico de criação da UNASUL (União das Nações Sul-Americanas).

internacional. Não somente uma nova linguagem era apresentada no documento, mas uma linguagem que expressava mudanças significativas que se colocavam a partir da eleição de novos governantes na América do Sul, muitos dos quais já naquelas alturas comprometidos com rupturas em relação ao projeto neoliberal preponderante durante a década de 1990, com o desenvolvimento de políticas comprometidas com o enfrentamento das históricas desigualdades, da pobreza e da miséria; mas, também, com novas visões acerca das relações da América Latina com as diferentes regiões do Planeta, não necessariamente comprometidas com a relação Norte-Sul.

Na continuidade, em 2005 foram realizados dois encontros dos chefes de Estado, o primeiro no mês de setembro, em Brasília, e o segundo em dezembro, em Montevideo. Para fins da análise aqui apresentada será considerada a Declaração Presidencial e Agenda Prioritária, documento que resultou do encontro realizado em Brasília. A referida Declaração inicia com a reafirmação de um conjunto de princípios que orientavam a construção da Comunidade Sul-Americana das Nações, apresenta um conjunto de condições institucionais de organização da Comunidade Sul-Americana das Nações e, por fim, define uma "agenda prioritária" da Comunidade (COMUNIDADE SULAMERICANA DAS NAÇÕES, 2005).

Em relação aos princípios e pressupostos fundadores da Comunidade SulAmericana das Nações, aquela Declaração indicou:

1. A essência da Comunidade Sul-americana de Nações é o entendimento político e a integração econômica e social dos povos da América do Sul.

2. A Comunidade Sul-americana de Nações fortalecerá a identidade da América do Sul e contribuirá, em coordenação com outras experiências de articulação regional e sub-regional, para o fortalecimento da integração dos povos da América Latina e do Caribe.

3. A associação recíproca dos Estados Partes do MERCOSUR e da CAN, assim como a associação do Suriname, da Guiana e do Chile, são essenciais para a conformação da Comunidade Sul-americana de Nações, com vistas à finalidade última da união sul-americana.

4. A Comunidade Sul-americana de Nações tem como objetivo o fortalecimento dos valores e princípios comuns estabelecidos na Declaração Presidencial de Cusco.

5. No campo econômico, os propósitos da Comunidade Sulamericana de Nações incluem o avanço e consolidação do processo de convergência rumo ao estabelecimento de uma zona de livre comércio sul-americana, com vistas a seu aperfeiçoamento, assim como a promoção do crescimento econômico e a redução das assimetrias, quando possível, mediante a complementação das economias dos países da América do Sul (COMUNIDADE SUL-AMERICANA DAS NAÇÕES, 2005, p. 27-29).

Em relação às áreas de ação prioritária da Comunidade Sulamericana de Nações, a Declaração de 2005 indicou: o diálogo político, a integração física, o meio ambiente, a integração energética os mecanismos financeiros sul-americanos, as assimetrias, a promoção da coesão social, da inclusão social e da justiça social, e as telecomunicações (COMUNIDADE SUL-AMERICANA DAS NAÇÕES, 2005, p. 31).

Um último encontro entre os chefes de Estado dos Países sul-americanos foi realizado antes daquele que, efetivamente, discutiu e tornou público o Tratado 
Do "regionalismo aberto" à proposta de uma comunidade sul-americana das nações: o processo histórico de criação da UNASUL (União das Nações Sul-Americanas).

Constitutivo da UNASUL: o encontro de Cochabamba, na Bolívia, realizado em dezembro de 2006. Um encontro que foi decisivo para a transformação da Comunidade SulAmericana das Nações em UNASUL. Naquele encontro, os chefes de Estado dos países sul-americanos, já numa perspectiva de concretização de um tratado de integração, discutiram sobre um "novo modelo de integração para o século XXI", os "princípios orientadores da integração sul-americana", as "premissas para a construção da integração sul-americana" e os "objetivos da integração" (DECLARAÇÃO DE COCHABAMBA, 2006).

A "Declaração De Cochabamba", documento resultante daquele encontro, inicia indicando a intenção de colocar "a pedra fundamental" do processo de integração sulamericana. Assinala, ainda no seu início, o interesse de fortalecer a cooperação sulamericana em todas as dimensões, indicando ser a comunidade sul-americana constituída pelos povos originários, pelos afrodescendentes, pelos imigrantes europeus e pelas "lutas sociais da região" (DECLARAÇÃO DE COCHABAMBA, 2006).

Quando se refere aos princípios orientadores da integração sul-americana, a Declaração indica seis princípios, quais sejam: 1. A solidariedade e a cooperação como estratégias de busca de maior equidade, redução da pobreza, diminuição das desigualdades e fortalecimento do multilateralismo como "princípio orientador das relações internacionais"; 2. Soberania, respeito à integridade territorial e autodeterminação dos povos, assegurando-se a prerrogativa dos Estados nacionais de decidirem sobre suas estratégias de desenvolvimento e de inserção em nível internacional, "sem ingerências externas em seus assuntos internos"; 3. Paz, indicandose a importância de afirmar a América do Sul como uma "Zona de Paz", na qual os conflitos internacionais se resolvam através de soluções pacíficas; 4. Democracia e pluralismo, para "consolidar a integração sem ditaduras" e de forma respeitosa aos direitos humanos e à dignidade humana, fazendo-se referência aos povos originários, aos afrodescendentes, aos imigrantes, "com igualdade de gênero e respeito a todas as minorias e suas manifestações linguísticas e culturais" e reconhecendo aos movimentos sociais e organizações da sociedade civil "seu direito a uma participação democrática em cada um dos Países sul-americanos e no processo de integração"; 5. Direitos humanos universais, interdependentes e indivisíveis, indicando-se a importância em "dar um impulso similar tanto ao desenvolvimento dos direitos civis e políticos, como aos direitos econômicos, sociais e culturais, reconhecendo o direito ao desenvolvimento como um direito substantivo, na égide integradora e multidisciplinar dos direitos humanos"; 6. Harmonia com a natureza, para um "desenvolvimento sustentável", garantindo-se que as preocupações ambientais e climáticas estejam presentes "em todas as iniciativas de desenvolvimento regional, fundamentalmente nas obras de infraestrutura e energia, preservando o equilíbrio dos ecossistemas e a proteção da biodiversidade, com reconhecimento e valorização dos conhecimentos tradicionais" (DECLARAÇÃO DE COCHABAMBA, 2006).

Já nesses princípios, a reafirmação de caminhos que a discussão sobre o processo integrativo sul-americano tomou principalmente a partir de 2004 , com a afirmação do processo integrativo como um processo de autodeterminação dos países sul- 
Do "regionalismo aberto" à proposta de uma comunidade sul-americana das nações: o processo histórico de criação da UNASUL (União das Nações Sul-Americanas).

americanos, dentro de uma concepção ampla de desenvolvimento, não centrada na dimensão econômica, mas integrando as dimensões socioculturais, políticas e ambientais.

Na mesma direção, os objetivos elencados para o processo integrativo contemplavam uma visão ampla de desenvolvimento, com ênfase ao enfrentamento das desigualdades e problemas sociais existentes nos Países sul-americanos. Daí que o documento indica prioridade a quatro objetivos: 1 . A superação das desigualdades para uma integração equitativa, com o "desenvolvimento de mecanismos concretos e efetivos que permitam resolver as grandes desigualdades que existem entre os Países e regiões da América do Sul; 2. A criação de um "Novo Contrato Social Sul-Americano", promovendo uma integração "com rosto humano articulada com a agenda produtiva", que se expresse no estabelecimento de metas definidas de desenvolvimento social e em mecanismos sistemáticos de avaliação"; 3. Integração energética para o bem-estar de todos, com a articulação de estratégias e políticas nacionais "para um aproveitamento dos recursos energéticos da região que seja integral, sustentável, solidário e que reconheça as desigualdades entre os Países e regiões"; 4. Infraestrutura para a interconexão dos povos e das regiões, promovendo a conectividade da região "a partir da construção de redes de transporte e telecomunicações que interconectem os Países, atendendo critérios de desenvolvimento social e econômicos sustentáveis para acelerar o processo de integração, preservando o ambiente o equilíbrio dos ecossistemas" (DECLARAÇÃO DE COCHABAMBA, 2006).

Além dos quatro objetivos referidos, a Declaração de Cochabamba anunciou como objetivo do processo integrativo sul-americano a "cooperação econômica e comercial", a "integração financeira sul-americana", numa perspectiva de construção de mecanismos financeiros de apoio ao desenvolvimento da região, a "integração industrial e produtiva", o desenvolvimento da "cidadania sul-americana", o desenvolvimento de uma política conjunta de migração, com preocupação de "proteção a todos os trabalhadores migrantes e suas famílias", a "identidade cultural" sul-americana, a "cooperação em matéria ambiental", a "participação cidadã" no processo integrativo e, pela primeira vez num documento resultante das reuniões realizadas desde o início dos anos 2000, "a cooperação em matéria de defesa", com a intenção de "continuar promovendo o intercambio informacional e de experiências em matéria de doutrinas e formação de pessoal entre os Ministérios de Defesa dos Países membros" (DECLARAÇÃO DE COCHABAMBA, 2006).

Chegou-se, então, ao ano de 2008, quando finalmente foi assinado o Tratado Constitutivo da UNASUL. Em encontro realizado em maio daquele ano, em Brasília, os chefes de Estado da Argentina, da Bolívia, do Brasil, do Chile, da Colômbia, do Equador, da Guiana, do Paraguai, do Peru, do Suriname, do Uruguai e da Venezuela assinaram o documento que constituiu a UNASUL, contendo o mesmo um preâmbulo e 27 artigos, além de um "artigo transitório", relacionado esse à designação de uma Comissão Especial visando a elaboração de um Protocolo Adicional, estabelecendo a composição, as atribuições e o funcionamento do Parlamento Sul-Americano (UNASUL, 2008). 
Do "regionalismo aberto" à proposta de uma comunidade sul-americana das nações: o processo histórico de criação da UNASUL (União das Nações Sul-Americanas).

No seu Preâmbulo, o Tratado Constitutivo da UNASUL afirma o compromisso dos Países membros com a "história compartilhada e solidária" das nações sul-americanas, "multiétnicas, plurilíngues e multiculturais", que "lutaram pela emancipação e unidade sul-americana, honrando o pensamento daqueles que forjaram nossa independência e liberdade em favor dessa união e da construção de um futuro comum". Além disso, ressalta a "determinação de construir uma identidade e cidadania sul-americanas e desenvolver um espaço regional integrado no âmbito político, econômico, social, cultural, ambiental, energético e de infraestrutura, para contribuir para o fortalecimento da unidade da América Latina e Caribe". Afirma, também, uma visão de integração pautada na ideia de um "desenvolvimento sustentável" e voltada ao bemestar dos povos sul-americanos ("contribuindo para resolver os problemas que ainda afetam a região, como a pobreza, a exclusão e a desigualdade social persistentes") e comprometida com o multilateralismo e com o alcance de um "mundo multipolar", "equilibrado e justo no qual prevaleça a igualdade soberana dos Estados e uma cultura de paz em um mundo livre de armas nucleares e de destruição em massa". E termina afirmando os princípios basilares do processo integrativo:

[...] irrestrito respeito à soberania, integridade e inviolabilidade territorial dos Estados; autodeterminação dos povos; solidariedade; cooperação; paz; democracia, participação cidadã e pluralismo; direitos humanos universais, indivisíveis e interdependentes; redução das assimetrias e harmonia com a natureza para um desenvolvimento sustentável (UNASUL, 2008. Tradução dos autores).

Dentre os artigos afirmados pelo Tratado Constitutivo da UNASUL, os principais referem-se aos objetivos, aos órgãos, institucionalidades e fontes jurídicas do Acordo Integrativo, à concertação política entre os Estados membros e relação com terceiros, à participação cidadã e à formação de um Parlamento Sul-Americano. Para os fins do presente artigo, é importante o registro dos objetivos apresentados pelo Tratado, bem como das questões relacionadas à concertação política entre os Estados membros e as relações com outros Estados. Quanto aos objetivos da UNASUL, seu Tratado Constitutivo assim os define:

\footnotetext{
A União de Nações Sul-americanas tem como objetivo construir, de maneira participativa e consensuada, um espaço de integração e união no âmbito cultural, social, econômico e político entre seus povos, priorizando o diálogo político, as políticas sociais, a educação, a energia, a infraestrutura, o financiamento e o meio ambiente, entre outros, com vistas a eliminar a desigualdade socioeconômica, alcançar a inclusão social e a participação cidadã, fortalecer a democracia e reduzir as assimetrias no marco do fortalecimento da soberania e independência dos Estados (UNASUL, 2008. Tradução dos autores).
}

Em relação à concertação política entre os Estados membros e a relação com outros Estados, o Tratado Constitutivo da UNASUL, além de ressaltar a importância da harmonia e respeito mútuo entre as partes, a defesa da democracia e a promoção dos direitos humanos, indica que: 
Do "regionalismo aberto" à proposta de uma comunidade sul-americana das nações: o processo histórico de criação da UNASUL (União das Nações Sul-Americanas).

Os Estados Membros reforçarão a prática de construção de consensos no que se refere aos temas centrais da agenda internacional e promoverão iniciativas que afirmem a identidade da região como um fator dinâmico nas relações internacionais (UNASUL, 2008. Tradução dos autores).

Apontando, claramente, a intenção de reforçar a participação da América do Sul na construção de uma agenda internacional de desenvolvimento. Quanto à relação com outros Estados, o Tratado assim se posicionou:

A UNASUL promoverá iniciativas de diálogo sobre temas de interesse regional
ou internacional e buscará consolidar mecanismos de cooperação com outros
grupos regionais, Estados e outras entidades com personalidade jurídica
internacional, priorizando projetos nas áreas de energia, financiamento,
infraestrutura, políticas sociais, educação e outras a serem definidas
(UNASUL, 2008. Tradução dos autores).

Numa indicação clara de que, naquelas alturas, como posição preponderante entre os governantes dos países membros da UNASUL, a dinâmica integrativa dos países sul-americanos com outras regiões do Planeta, embora não necessariamente excluísse a relação Norte - Sul, se orientava também por uma perspectiva de relações Sul - Sul, além da constituição de outras formas de articulação global, capazes de projetar no contexto internacional países sul-americanos com maior visibilidade e importância.

\section{Considerações finais}

O Tratado Constitutivo da UNASUL consolidou um processo histórico de diálogo entre os países sul-americanos, iniciado, sob o ponto de vista das discussões concretas e visando a constituição de um acordo integrativo, no final da década de 1990 e início da década de 2000. Iniciou, portanto, num contexto histórico em que a maioria dos países sul-americanos, sob o ponto de vista das orientações políticas e econômicas adotadas pelos governos nacionais, estava alinhada ao ideário neoliberal e à discussão sobre a criação de uma área de livre comércio envolvendo todo o Continente Americano, como projetado pelos governos dos Estados Unidos durante a década de 1990 e objetivado através da criação da ALCA.

Ao longo da primeira década do século XXI, no entanto, em praticamente todos os países da América do Sul assumiram forças sociais e políticas que promoveram rupturas com a orientação neoliberal adotada durante a década de 1990, orientando suas políticas econômicas a partir de novas concepções que, ainda que não tenham rompido completamente com o ideário neoliberal, recolocaram a atuação do Estado como estratégica não somente na dinamização das economias nacionais, mas, também, no desenvolvimento de políticas de enfrentamento das desigualdades sociais e econômicas que caracterizam historicamente toda a América do Sul. 
Do "regionalismo aberto" à proposta de uma comunidade sul-americana das nações: o processo histórico de criação da UNASUL (União das Nações Sul-Americanas).

Essas mudanças no contexto político da América Latina repercutiram significativamente no processo de discussão e de formatação do processo integrativo que resultou na criação da UNASUL. Uma nova concepção de desenvolvimento, uma nova concepção de integração, uma nova visão acerca das relações entre a América Latina e outras regiões do Planeta, uma nova visão acerca da importância da América do Sul no contexto internacional tornaram-se presentes, definindo os horizontes políticos e ideológicos que se objetivaram no Tratado Constitutivo da UNASUL.

Como evidenciado nos diferentes documentos produzidos nos encontros entre os chefes de Estado, desde o início dos anos 2000, aos poucos a concepção de desenvolvimento centrada na dimensão econômica, na abertura dos mercados, no fortalecimento da economia sul-americana para alcançar níveis mais elevados de competitividade na economia global e num contexto de mundialização do capital cedeu espaço para uma nova concepção de desenvolvimento, não mais exclusiva à dimensão econômica, mas integrando as dimensões cultural, social, política, ambiental, espacial. Sob o ponto de vista dos documentos que foram se apresentando, a dimensão econômica passou a ser, cada vez mais, condicionada pelas preocupações com as desigualdades sociais, com a pobreza e a exclusão social, com a necessidade de políticas de geração de trabalho e de renda, com o respeito à diversidade cultural e à memória dos povos, com a participação cidadã, com a sustentabilidade ambiental e ecológica.

A concepção de desenvolvimento que se tornou visível no decorrer das discussões sobre o processo integrativo redefiniu a própria concepção de integração entre os países, mais especificamente, entre os países sulamericanos. Uma integração não somente econômica, não somente visando aumentar a competitividade das economias nacionais da própria Região na economia globalizada, não mais orientada somente a partir do pressuposto do livre comércio, mas uma integração que se objetivou na própria ideia e concepção de uma "comunidade das nações sul-americanas", enfatizando-se as dimensões históricas, das lutas dos povos, da construção da cidadania, da afirmação da região como uma "região de paz", do horizonte de emancipação e de afirmação da diversidade sociocultural que constitui os povos sul-americanos.

Essa concepção de integração que foi sendo tecida nas discussões que resultaram na criação da UNASUL redefiniu, também, a visão acerca das relações da América do Sul com outras regiões do Planeta. Se, no início das discussões, a posição hegemônica era de integração da América do Sul no projeto liderado pelos Estados Unidos, de criação da ALCA, em 2008 a maioria dos países sulamericanos tinha se posicionado contra aquela criação e cada vez mais afirmavase a visão de relações variadas, com diferentes regiões do Planeta. Não se pode esquecer que, naquelas alturas, o Brasil, enquanto principal País da América do Sul, já participava das discussões que resultaram na formação do BRICs, envolvendo, além do Brasil, a Rússia, a China, a Índia e a África do Sul. Além disso, sob o ponto de vista da diplomacia, cada vez mais os governos sul-americanos 
Do "regionalismo aberto" à proposta de uma comunidade sul-americana das nações: o processo histórico de criação da UNASUL (União das Nações Sul-Americanas).

afirmavam a importância, comprometendo-se efetivamente em diálogos e projetos, do fortalecimento das relações Sul-Sul (entre os povos sul-americanos e os povos africanos e asiáticos, em especial).

Nessa direção, inclusive, se colocavam novas visões e novas pretensões quanto a participação política dos Países e da América Latina no contexto internacional. Naquelas alturas de 2008, o Brasil já projetava maior participação nas instituições internacionais (como é o caso, por exemplo, do Conselho de Segurança da ONU, já colocada no horizonte da diplomacia brasileira naquele momento), além de afirmar cada vez maior compromisso com instituições de poder não necessariamente vinculadas às instituições formatadas a partir do século XX sob a hegemonia dos Estados Unidos e da Europa; como é o caso da própria participação nos BRICs, mas, também, na ênfase dada ao G-20. Como apresentado nos documentos, uma visão afirmativa de que a América do Sul deveria atuar no contexto internacional com maior autonomia, numa perspectiva de afirmação de suas singularidades, mas, também, a própria afirmação da região como uma "região de paz", colocavam-se como indicações do interesse partilhado entre muitos países participantes da UNASUL em redefinir a atuação e a participação da América Latina no contexto de distribuição do poder global.

\section{Referências}

BRASIL. Brasil fortalece relação com membros do Mercosul. In: http://www.brasil.gov.br/economia-e-emprego/2017/05/brasil-fortalecerelacao-com-membros-do-mercosul. Consulta em 29 jun. 2017.

CEPAL. El regionalismo abierto en América Latina y el Caribe La integración económica al servicio de la transformación productiva con equidad. 1994. Disponível em: <http://repositorio.cepal.org/bitstream/handle/11362/2140/1/S9481108_es.p df>. Acesso em: 08 abr. 2017.

COMUNICADO DE BRASÍLIA. Reunião de Presidentes da América do Sul. 2000. Disponível em:<http://www.oei.es/historico/oeivirt/cimeira1.htm>. Acesso em: 03 abr. 2017.

COMUNIDADE SUL-AMERICANA DAS NAÇÕES. Declaração Presidencial e Agenda Prioritária. 2005. Disponível em: <http://funag.gov.br/loja/download/285-Comunidade_Sul-

Americana_de_Nacoes.pdf>. Acesso em: 08 abr 2017.

CONSENSO DE GUAYAQUIL. Consenso de Guayaquil sobre Integración, Seguridad e Infraestructura para el Desarrollo. II Reunión de Presidentes de América del Sur. 2002. Guayaquil, Equadot. Disponível em: <http://www19.iadb.org/intal/intalcdi/PE/2010/05282.pdf>. Acesso em 08 abr 2017. 
Do "regionalismo aberto" à proposta de uma comunidade sul-americana das nações: o processo histórico de criação da UNASUL (União das Nações Sul-Americanas).

CORAZZA, Gentil. O "regionalismo aberto" da CEPAL e a inserção da América Latina na globalização. Ensaios FEE, Porto Alegre, v. 27, n. 1, p. 135-152, maio 2006.

DECLARAÇÃO DE COCHABAMBA. Declaración de Cochabamba Colocando la Piedra Fundamental para una Unión Sudamericana. 2006. Disponível em:< https://repo.unasursg.org/alfresco/service/unasursg/documents/content/DECL ARACION_DE_COCHABAMBA_COLOCANDO_LA_PIEDRA_FUNDAMENTAL_PAR A_UNA_UNION_SUDAMERICANA.pdf?noderef=291f5cf3-5ad2-4a46-9c49b94b68682505>. Acesso em: 10 abr 2017.

DECLARAÇÃO DE CUSCO. Declaração de Cusco sobre a Comunidade SulAmericana de Nações. 2004. Disponível em: <http://www.isagsunasur.org/uploads/biblioteca/1/bb[610]ling[1]anx[1824].pdf>. Acesso em: 08 abr 2017.

GOMES, Kelly da Rocha. Unasul: mais do mesmo? As dimensões do processo de integração sul-americano. 2012. 234 f. Dissertação (mestrado) UNESP/UNICAMP/PUC-SP, Programa San Tiago Dantas, 2012. Disponível em: <http://hdl.handle.net/11449/93740>.

KAPLAN, Marcos. Problemas del desarrollo y de la integración en América Latina. Caracas: Monte Avila Editores C.A, 1968.

REINOSO, Alan, F. Las Relaciones Comunidad Andina - Unión Europea y la Zona de Libre Comercio del Sur. Lima: PUCP, 2000.

UNASUL. Tratado Constitutivo de la Unión de Naciones Suramericanas. 2008. Disponível em: $<$ https://repo.unasursg.org/alfresco/service/unasursg/documents/content/TRA TADO_CONSTITUTIVO_DE_LA_UNION_DE_NACIONES_SURAMERICANAS.pdf?n oderef $=44 d 79020-e 810-4 d 55-99 f 7-7 f 0 a e 5 d b 23 e c>$. Acesso em: 16 out 2016.

VIEIRA, Jeferson de Castro. As experiências de integração da ALALC e ALADI. Revista de Estudos e Pesquisas sobre as Américas, v. 9, n.

Sobre os autores:

Carolina de Oliveira, Graduada em Relações Internacionais, é Mestre em Desenvolvimento Regional pela Universidade de Santa Cruz do Sul. UNISC (Universidade de Santa Cruz do Sul). Email: carolina2@unisc.br

Marco André Cadoná, Doutor em Sociologia Política pela Universidade Federal de Santa Catarina - UFSC, professor e pesquisador na Universidade de Santa Cruz do Sul - UNISC.Email: mcadona@unisc.br 